\title{
A study of the aqueous phase equilibria involving the $\mathrm{Fe}(\mathrm{VI})$ species
}

TOMMASO BARONI $^{1 *}$, FRANCESCO Di BENEDETTO ${ }^{1}$ AND GIORDANO MONTEGROSSI ${ }^{2}$

${ }^{1}$ Department of Earth Sciences, University of Florence, Via Giorgio La Pira 4, 50121 Florence, Italy (*correspondence: tommaso.baroni@unifi.it)

${ }^{2} \mathrm{CNR}$, Institute of Geosciences and Earth Sciences, Via Giorgio la Pira, 4, 50121 Firenze, Italy

Ferrates (VI) are powerful oxidizing agents both in acidic and basic solutions; treatment of all kind of water sources collected worldwide have demonstrated their capability of removing a wide range of organic and inorganic compounds. Additionally, during the oxidation process, the $\left[\mathrm{FeO}_{4}\right]^{2-}$ anions reacting with water lead to the in situ formation of $\mathrm{Fe}$ oxyhydroxide nanoparticles, which serve as an efficient adsorbent for oxidized pollutants and suspended/colloidal materials. However, these findings have not yet fully exploited to practical applications due to difficulties associated with the relatively low production yield and the limited stability field, as a function of $\mathrm{pH}, \mathrm{T}$, concentration and co-existing ions. Results of kinetic studies have shown the complexity of ferrates (VI) decay in aqueous solutions, with the formation of both oxygen and hydrogen peroxide together with a plethora of short-living intermediates. Despite the deeper knowledgegrade recently achieved, the results are not fully consistent, lacking a proper up-to-date overview on the relative thermodynamics and stability in water. Using PHREEQC, this study critically reviews the aqueous phase-equilibria of ferrate and the related aqueous species/complexes over the whole $\mathrm{pH}$ range through a specific updated Pourbaix diagram, focused on the stability region for the high-valent iron compounds. Results point out that the standard $\left[\mathrm{FeO}_{4}\right]^{2-}$ stability field is further reduced while accounting for the presence of $\mathrm{Fe}(\mathrm{OH})_{4}^{-}$[1], which is slightly more stable than $\mathrm{Fe}(\mathrm{OH})_{3}$. An additional new factor considered in regards to the previous studies is the $\mathrm{O}_{2}$ partial pressure which, once increased to $1 \mathrm{~atm}$, seems to extend the stability/predominance field of ferrate species. A set of laboratory experiments will follow in order to validate the computational results.

[1] Diakonov (1999) Geochim. Cosmochim. Ac. 63, 2247-2261 